\title{
Perioperative Management of Antiplatelet Therapy in Patients With History of Coronary Artery Disease Undergoing Surgery for Esophageal Cancer: A Single-center Experience
}

\author{
DIMITRIOS SCHIZAS ${ }^{1,2}$, NIKOLETTA A. THEOCHARI ${ }^{2}$, CHRISTINA A. THEOCHARI $^{2}$, \\ DAMIANOS G. KOKKINIDIS ${ }^{3}$, VASILEIA DOMI ${ }^{4}$, EUSTRATIA MPAILI ${ }^{1}$, ANIL KUMAR JONNALAGADDA ${ }^{5}$, \\ ALKISTIS KAPELOUZOU ${ }^{1}$, ANARGYROS BAKOPOULOS ${ }^{4}$ and THEODORE LIAKAKOS ${ }^{1}$ \\ ${ }^{1}$ First Department of Surgery, National and Kapodistrian University of Athens, \\ Laikon General Hospital, Athens, Greece; \\ ${ }^{2}$ Surgery Working Group, Society of Junior Doctors, Athens, Greece; \\ ${ }^{3}$ Department of Medicine, Jacobi Medical Center, Albert Einstein College of Medicine, Bronx, NY, U.S.A.; \\ ${ }^{4}$ Third Department of Surgery, National and Kapodistrian University of Athens, \\ Attikon University Hospital, Athens, Greece; \\ ${ }^{5}$ Department of Cardiology, Medstar Washington Hospital Center, Washington, DC, U.S.A.
}

\begin{abstract}
Aim: To present the experience of the upper Gastrointestinal Unit of the Surgical Department of National and Kapodistrian University of Athens in order to inform surgeons of the exact harms and benefits associated with their decisions concerning management of antiplatelet therapy. Materials and Methods: This was a single-center study of patients who underwent surgery for esophageal cancer and had concomitant coronary artery disease from 1/1/2005 to 31/7/2017. Patients were divided into two cohorts based on when their antiplatelet therapy was stopped $(<7$ vs. $\geq 7$ days). Esophageal cancer was classified as esophageal only or as Siewert type I, II, or III based on tumor location at the gastroesophageal junction. A univariate logistic regression model was developed to assess the relationship between baseline variables and myocardial infraction, mortality, bleeding and stroke after the operation. For all tests, differences with a value of $p<0.05$ were considered significant. Results: During the study period, 135 esophagectomies were performed for esophageal cancer. Almost $17 \%$ of them had concomitant coronary artery disease medically managed with antiplatelet therapy. No difference was found in terms of myocardial infarction,
\end{abstract}

This article is freely accessible online.

Correspondence to: Nikoletta A. Theochari, MS, 29 Parnithos, 16344 Ilioupolis, Athens, Greece. Mobile: +30 6981532771, e-mail: nickyth12@gmail.com

Key Words: Esophageal cancer, preoperative management, coronary artery disease, coronary stents, antiplatelet therapy. stroke or severe bleeding events between patients that stopped antiplatelet therapy for more or less than 7 days before esophagectomy. Conclusion: It is a reasonable approach to discontinue antiplatelet therapy for more than 7 days before surgery, especially in such a population of patients with esophageal cancer that require complex operations with high bleeding risk.

Esophageal cancer is the ninth most common cancer and the sixth most common cause of cancer-related death globally and affects more than 450,000 people worldwide $(1,2)$. Despite advancements in therapeutic options, overall survival of patients with esophageal cancer remains poor, and the 1- and 5-year survival rates are estimated to be close to $78 \%$ and $42 \%$, respectively (3). There are two main types of esophageal cancer: esophageal squamous cell carcinoma and esophageal adenocarcinoma (4), and esophagectomy is the main treatment option for both of them, while the role of multimodality therapy (with chemotherapy and radiotherapy) is also important for optimization of prognosis (5). A number of patients with esophageal cancer who are candidates for esophageal surgery also have concomitant coronary artery disease (CAD), while some have additional history of stent placement secondary to risk of stent thrombosis (ST) and should be on antiplatelet therapy (APT) with aspirin and purinergic P2Y12 inhibitor (6) (traditionally clopidogrel but contemporary surgeons also have to deal with alternative medications such as ticagrelor or prasugrel). The perioperative management of these patients and questions such as the ideal timing of APT discontinuation preoperatively, bridging options with other antithrombotic medications and resuming APT after surgery, have only been partially answered. The latest guidelines from 2014 from the 
Table I. Baseline characteristics of patients that discontinued APT prior to surgery.

\begin{tabular}{|c|c|c|c|c|c|}
\hline \multirow[b]{2}{*}{ Characteristic } & & \multicolumn{4}{|c|}{ Discontinuation of APT prior to surgery } \\
\hline & & Total $(\%)$ & $\geq 7$ Days & $<7$ Days & $p$-Value \\
\hline \multirow[t]{2}{*}{ Gender, n (\%) } & Female & $4(21.1)$ & $2(22.2)$ & $2(20)$ & $>0.99$ \\
\hline & Male & $15(78.9)$ & $7(77.8)$ & $8(80)$ & \\
\hline Age, years & Mean \pm SD & $67.91 \pm 8.9$ & $64.7 \pm 10.7$ & $70.6 \pm 8.1$ & \\
\hline Intervention before surgery, months & Mean \pm SD & $75.1 \pm 60.3$ & $85.1 \pm 73.4$ & $57 \pm 19.9$ & 0.151 \\
\hline MI before surgery, years & Mean \pm SD & $11.4 \pm 7.1$ & $10.1 \pm 5.1$ & $11.2 \pm 10$ & 0.738 \\
\hline Follow up after surgery, months & Mean \pm SD & $37.1 \pm 41.9$ & $30.1 \pm 34.9$ & $37.5 \pm 39.8$ & 0.742 \\
\hline Death after surgery, months & Mean \pm SD & $26.3 \pm 47.2$ & $0.7 \pm 0.5$ & $10.5 \pm 7.9$ & 0.508 \\
\hline Days before surgery that APT stopped & Mean \pm SD & $9.6 \pm 7.8$ & $15 \pm 8.8$ & $5.1 \pm 2.1$ & 0.083 \\
\hline Hypertension, n (\%) & Hypertension & $19(100)$ & $9(100)$ & $10(100)$ & 0.82 \\
\hline Hyperlipidemia, n (\%) & Hyperlipidemia & $14(73.7)$ & $7(77.8)$ & $7(70)$ & $>0.99$ \\
\hline $\mathrm{DM}, \mathrm{n}(\%)$ & $\mathrm{DM}$ & $4(21.1)$ & $2(22.2)$ & $2(20)$ & $>0.99$ \\
\hline CAD, n $(\%)$ & CAD & $18(5.3)$ & $9(100)$ & $9(90)$ & $>0.99$ \\
\hline Peripheral artery disease, $\mathrm{n}(\%)$ & Present & $3(15.8)$ & $0(0)$ & $3(30)$ & 0.211 \\
\hline History of coronary intervention, $\mathrm{n}(\%)$ & Yes & $14(73.7)$ & $9(100)$ & $5(50)$ & 0.033 \\
\hline \multirow[t]{4}{*}{ Type of intervention, $\mathrm{n}(\%)$} & PTA & $1(7.1)$ & $0(0)$ & $1(20)$ & 0.123 \\
\hline & PTA and stent & $7(50)$ & $4(44.4)$ & $3(60)$ & \\
\hline & CABG & $4(28.6)$ & $4(44.4)$ & $0(0)$ & \\
\hline & Both & $2(14.3)$ & $1(11.1)$ & $1(20)$ & \\
\hline 3-Vessel disease & Present & $4(23.5)$ & $4(44.4)$ & $0(0)$ & 0.082 \\
\hline History of MI & Yes & $15(78.9)$ & $8(88.9)$ & $7(70)$ & 0.582 \\
\hline Atrial fibrillation & Present & $1(5.3)$ & $1(11.1)$ & $0(0)$ & 0.474 \\
\hline History of any bleeding & Yes & $3(15.80$ & $3(33.3)$ & $0(0)$ & 0.087 \\
\hline CKD & Present & $19(100)$ & $9(100)$ & $10(100)$ & 0.163 \\
\hline History of stroke/TIA & Yes & $1(5.3)$ & $0(0)$ & $1(10)$ & $>0.99$ \\
\hline
\end{tabular}

MI: Myocardial infarction; DM: diabetes mellitus; CAD: coronary artery disease; PTA: percutaneous transluminal angioplasty; CABG: coronary artery bypass graft; CKD: chronic kidney disease; TIA: transient ischemic attack.

American Heart Association (AHA) and American College of Cardiology (ACC) recommend elective operations be delayed for up to 1 year after placement of drug-eluting stents (DES) and for 1 month for bare-metal stents (BMS) $(7,8)$. On the other hand, APT therapy should be continued when there is a need for urgent operations within the first 6 weeks after stent placement unless there are specific indications showing for this individual patient that the risk of bleeding is higher than that of ST (8). Surgery for esophageal cancer involves complex operations that usually oblige surgeons to work in both abdominal and thoracic cavity for hours, thus predisposing patients to a considerable bleeding risk. This is why we believe it is important for esophageal cancer surgeons to know the exact harms and benefits associated with their decisions concerning management of APT. Given the paucity of data on this topic, here we present the experience of the Upper Gastrointestinal (GI) Unit of the Surgical Department of National and Kapodistrian University of Athens.

\section{Materials and Methods}

The current analysis includes patients from the Surgical Department of National and Kapodistrian University of Athens. The study protocol was approved by the Institutional Review Board (Approval number: 342/31092017). Demographic, clinical, procedural data and outcomes were obtained from electronic medical records. Patient baseline and clinical characteristics were prospectively collected and entered into the esophageal surgery database. All records were reviewed by trained chart abstractors and verified by a Boardcertified general surgeon. All patients included in this study had concomitant CAD and underwent esophageal surgery from 1/1/2005 to $31 / 7 / 2017$. All operations were performed by experienced upper GI surgeons.

Data were collected for the following baseline variables: gender, age, hypertension; hyperlipidemia; diabetes mellitus; atrial fibrillation; chronic kidney disease; CAD; peripheral and carotid artery disease; history of myocardial infarction (MI) or stroke; time from MI and coronary intervention to esophageal surgery; history, timing, and type of percutaneous coronary intervention (percutaneous transluminal angioplasty with/without stenting; coronary artery bypass graft, a combination of these techniques); type and number of stents used; coronary artery vessel affected; presence of three-vessel disease; type of APT therapy (aspirin only, clopidogrel only, dual APT); treatment with coumadin or newer oral anticoagulants before surgery; when was APT stopped and restarted; bridging used and type of bridging; history of any type of bleeding while on antithrombotic therapy; type of esophageal cancer (esophagus only vs. Siewert type I; II; III); type of esophageal surgery (esophagectomy vs. esophagogastrectomy); use of 


\begin{tabular}{|c|c|c|c|c|c|}
\hline & & \\
\hline & & Total, n (\%) & $\geq 7$ Days & $<7$ Days & $p$-Value \\
\hline \multirow[t]{4}{*}{ Type of EC } & Only esophagus & $3(15.8)$ & $0(0)$ & $3(30)$ & \multirow[t]{4}{*}{0.355} \\
\hline & Siewert I & $8(42.1)$ & $3(33.3)$ & $5(50)$ & \\
\hline & Siewert II & $5(26.3)$ & $4(44.4)$ & $1(10)$ & \\
\hline & Siewert III & $3(15.8)$ & $2(22.2)$ & $1(10)$ & \\
\hline \multirow[t]{2}{*}{ Type of surgery } & Total esophagectomy & $6(31.6)$ & $2(22.2)$ & $4(40)$ & \multirow[t]{2}{*}{0.628} \\
\hline & Esophagogastrectomy & $13(68.4)$ & $7(77.8)$ & $6(60)$ & \\
\hline CRT & Neoadjuvant & $3(16.7)$ & $1(12.5)$ & $2(20)$ & $>0.99$ \\
\hline Adjuvant CRT & Adjuvant & $5(29.4)$ & $3(37.5)$ & $2(22.2)$ & 0.620 \\
\hline \multirow[t]{3}{*}{ Before intervention } & Aspirin & $16(84.2)$ & $7(77.8)$ & $9(90)$ & 0.582 \\
\hline & Clopidogrel & $7(36.8)$ & $5(55.6)$ & $2(20)$ & 0.170 \\
\hline & Coumadin/NOACS & $2(10.5)$ & $1(11.1)$ & $1(10)$ & $>0.99$ \\
\hline Use of Bridging & Yes & $19(100)$ & $9(100)$ & $10(100)$ & 0.82 \\
\hline MI after surgery & Yes & & $1(0.11)$ & 0 & $>0.99$ \\
\hline Stroke after surgery & Yes & $0(0)$ & $0(0)$ & $0(0)$ & $>0.99$ \\
\hline Death & Yes & $5(29.4)$ & $2(25)$ & $3(33.3)$ & $>0.99$ \\
\hline
\end{tabular}

EC, Esophageal cancer; CRT, chemoradiotherapy; NOACS, new oral anticoagulant; MI, myocardial infarction.

neoadjuvant or adjuvant chemotherapy; months of follow-up after esophagectomy; and the following outcomes: Death, MI, stroke. Patients were divided in two cohorts based on when their APT was stopped ( $<7$ days $v s . \geq 7$ days). Esophageal cancer was classified as esophageal only or as Siewert type I, II, III based on location at the gastroesophageal junction. The diagnosis of CAD was based on prior coronary angiography and confirmation of the disease. All patients were followed-up after their operation with a clinic visit or, when not possible, with a phone call.

The primary outcomes of our study were the risk of severe surgical bleeding and the risk of MI or stroke in the perioperative period. For each outcome, a direct comparison between patients with discontinuation of APT $<7$ days before the operation and patients where APT was discontinued $\geq 7$ days before the operation was conducted.

Statistical analysis. Categorical variables are presented as absolute and relative frequencies and are compared with Chi-squared and Fisher's exact tests. Continuous variables are presented as means \pm standard deviations and are compared using the Wilcoxon rank-sum test. A univariate logistic regression model was developed to assess the relationship between baseline variables and MI, mortality, bleeding and stroke after the operation. For all tests, a value $p<0.05$ was considered significant. All analyses were performed using STATA software (Version 14.1; STATA Corporation, College Station, TX, USA).

\section{Results}

During the study period, 135 esophagectomies were performed for esophageal cancer. Of these, there were 23 patients with confirmed CAD. The results of our study are summarized in Tables I and II. Among these 23 cases, data on when APT was stopped before the operation was known for 19 patients ( $<7$ days before the operation in 10 patients, and $\geq 7$ days before the operation in nine patients). The average age was $67.9 \pm 8.9$ years and the predominant gender was male (79\%). Hypertension and hyperlipidemia were prevalent in 22/23 and 18/23 patients respectively, while four patients had diabetes and five concomitant peripheral artery disease. There were three patients with history of GI bleeding. The most common type of esophageal cancer overall was Siewert I (42.1\%), without a difference between the two groups. There were seven total esophagectomies and 16 esophagogastrectomies, without a difference between the two groups with APT data. Neoadjuvant chemotherapy was used in four out of 19 patients and adjuvant chemotherapy was used in six patients. The average follow-up period in months was $37.5 \pm 39.8$ months.

Seventeen out of 23 patients were on aspirin. Seven out of 23 patients were on clopidogrel before the operation and except one (history of stroke while on aspirin), the rest had a history of stenting. In six of them, clopidogrel was stopped $>7$ days before esophageal surgery, while in one patient clopidogrel was stopped 5 days before the surgery. Five out of seven patients on clopidogrel were on concomitant treatment with aspirin. The average time for discontinuation of APT before surgery was $9.58 \pm 7.78$ days. In the majority of cases, APT was restarted more than 10 days after surgery, apart from two cases, where it was restarted on the seventh and ninth day, respectively.

There were no major postoperative bleeding events in any of our patients. Only one MI occurred in the whole cohort, on the second postoperative day. This patient had a history of atrial fibrillation and known CAD in his left main coronary artery and was on treatment with aspirin. For this 
patient, aspirin was discontinued 13 days before the operation and $40 \mathrm{mg}$ enoxaparin daily was used for bridging until surgery. Postoperatively, $60 \mathrm{mg}$ enoxaparin daily was used for the first 3 days. For the next 5 days, aspirin was added, while from the ninth day and on, clopidogrel was also added to the therapeutic regimen. The patient died 3 months postoperatively due to ventilator-associated pneumonia.

\section{Discussion}

This was a single-center study of patients who underwent surgery for esophageal cancer and had concomitant CAD, which to the best of our knowledge is the first that specifically presents data on perioperative APT in such patients and the outcomes associated with that. Our results can be best summarized as follows: i) Almost $17 \%$ of our total esophagectomy population had concomitant CAD medically managed with APT; ii) the distribution between the two groups for APT discontinuation ( $<7$ days $v s . \geq 7$ days) was equal; iii) in total, 17/23 patients were on aspirin, while seven took clopidogrel; iv) the mean time for discontinuation of APT before surgery was 10 days; v) perioperative bridging was used in all cases between APT discontinuation and resumption after surgery, vi) APT was not restarted until 10 days after surgery; vii) our approach handling these cases was safe for our patients, with almost no adverse events that can be attributed to the perioperative APT management.

Among the more than 600,000 patients who have stents implanted in their coronary arteries annually, close to $25 \%$ will require non-cardiac surgery within 2 years of percutaneous coronary intervention (9). These patients face an increased risk of adverse events including MI, death and major adverse cardiovascular events (MACE) in the case of early discontinuation of APT therapy, secondary to ST (10-12). Compared to BMS, use of DES, even if representing a more advanced form of treatment strategy, has a higher and more prolonged risk of ST (10). Second- and third-generation DES offer the advantage of lower risk of ST compared to earlier DES. The latest ACC/AHA guideline focused update recommends delaying elective non-cardiac surgery by up to 6 weeks after BMS placement and up to 6 months after DES placement (13). However, if benefits associated with earlier operation outweigh the risks, it would be reasonable to proceed to surgery even 3 months after DES placement $(13,14)$.

Given the absence of randomized data on this topic, the current level of evidence is based on data from real-world observational studies and a recent large systematic review that synthesized the available information. The heterogeneity of the published studies in terms of outcomes studied, APT regimens, and decisions on discontinuation and restarting of APT, make it impossible to perform adequate quantitative collation for a meta-analysis and limit the interpretation for qualitative synthesis from systematic review. Moreover, the majority of the published data originate from a mixed surgical population without homogeneous surgical and bleeding risks or urgency levels. A recent systematic review on this topic supports the notion that based on the current data, there is not an ideal decision on when APT should be discontinued before esophagectomy, since there are not enough data to support a specific time period (6). The largest study on this topic to date was a case-control study with 42,000 non-cardiac surgeries, which showed that discontinuation of APT $>5$ days before the operation was not associated with different outcomes compared to other approaches (9). Moreover, there were no indications that a specific APT regimen strategy (dual APT, single APT with aspirin only or clopidogrel only) can be associated with lower risk of MACE or bleeding (6). Other interesting data from previous important studies show that the higher risk of ST associated with DES (at least first-generation) does not translate to higher risk of MACE compared to BMS in patients who will undergo operations. Moreover, the only clear risk factor for the occurrence of MACE perioperatively is recent stent implantation. According to the major casecontrol study from the Veterans Affairs (VA) system, there was an inverse relationship between the time from stent implantation to MACE occurrence, and MACE risk can be optimized by a time period longer than 6 months $(9,12)$. In light of these findings, ACC/AHA recommendations for a 6month period in DES gain even greater significance.

Despite the fact that current data show that there is no difference between available APT strategies in surgical patients in general, specific data on esophageal operations are very limited throughout the literature. Thus, it is unknown if for operations with a high risk for bleeding, such as esophagectomy, continuation of APT close to the operation date can be so liberal. Our group presents a dedicated cohort of patients who underwent esophagectomy for cancer who had concomitant CAD, without differences in regards to clinical outcomes between early ( $>7$ days) and late ( $<7$ days) discontinuation of APT. A cut-off point of 7 days was selected in our study because in our experience and in the absence of clear recommendations on APT discontinuation, 7 days is a usual recommendation by consulting cardiologists which is also reasonable for the majority of surgeons. Even if current data do not support there being a higher risk for more aggressive APT before surgery, the paucity of data on esophagectomy and the fact that in our experience these cases are usually associated with higher bleeding risk meant we were reluctant to risk discontinuation closer to the surgery date.

All cases included in our database were intervened on an elective setting. Esophageal cancer has a poor prognosis and timely surgery is an important part of its management (5). However, when possible, these operations should be delayed long enough to overcome the 6-week time period in BMS and 
6-month in DES. The role of neoadjuvant chemotherapy is crucial in cases like these, since it can be a solid therapeutic tool to precede the operation and improve the surgical outcomes, and at the same time delay the need for APT discontinuation. For the extremely rare cases of esophageal cancer where an urgent operation is needed, esophagectomy should be performed without stopping APT if the time period from stent placement is less than 6 weeks. Otherwise, it would be reasonable to hold the APT regimen. Fortunately, the majority of these cases are managed on a non-urgent basis.

\section{Limitations}

Our results should be interpreted in the context of limitations associated with retrospective observational research. This project was a single-center observational study, with a limited number of available patients. Secondary to our very limited sample, we were unable to detect significant differences between the two groups. However, this preliminary study is an initial step for consideration and more awareness among upper GI surgeons regarding APT management in esophagectomy for esophageal cancer, in the absence of other data right now.

\section{Conclusion}

This was the first dedicated cohort on patients with esophageal cancer undergoing esophagectomy who had CAD as a comorbidity and were being treated with APT. Despite our limited sample, our results can be interpreted as a preliminary specific data on the unique characteristics of esophagectomies when it comes to APT management. We confirmed previous published data on surgical cases which showed that the timing of APT discontinuation is not associated with bleeding, MI, death or MACE by expanding them specifically to esophageal cases. Unfortunately, the paucity of data on this topic is not solved with this study alone and more future studies are needed. We would recommend that elective esophageal surgeries should be delayed enough to meet ACC/AHA time period recommendations. Moreover, given that APT discontinuation more than 5 days before surgery is not associated with increased ST or MACE risk, we believe that it is a reasonable approach to discontinue APT more than 5-7 days before surgery until further data from larger studies show that there is not a higher bleeding risk in esophageal cases where APT was held less than 5-7 days before the operation.

\section{Ethical Statement}

All Authors confirm that this work conforms to the guidelines set forth in the Helsinki Declaration of 1975, as revised in 2000 , concerning Human and Animal Rights, and that the policy concerning Informed Consent was followed.

\section{Conflicts of Interest}

None declared.

\section{Authors' Contributions}

Study concept and design: Schizas, Liakakos, Theochari NA, Theochari CA, Kokkinidis; Acquisition of data: Theochari NA, Theochari CA, Kokkinidis, Schizas, Domi, Mpaili; Analysis and interpretation of data: Theochari NA, Schizas, Theochari CA, Bakopoulos, Kapelouzou; Drafting of the manuscript: Schizas, Theochari NA, Kokkinidis, Theochari CA, Mpaili, Domi; Critical revision of the manuscript for important intellectual content: Schizas, Jonnalagadda, Liakakos, Kokkinidis, Theochari NA, Theochari CA.

\section{References}

1 Jemal A, Bray F, Center MM, Ferlay J, Ward E and Forman D: Global cancer statistics. CA Cancer J Clin 61: 69-90, 2011. PMID: 21296855, DOI: 10.3322/caac.20107

2 Fitzmaurice C, Dicker D, Pain A, Hamavid H, Moradi-Lakeh M, MacIntyre MF, Allen C, Hansen G, Woodbrook R, Wolfe C, Hamadeh RR, Moore A, Werdecker A, Gessner BD, Te Ao B, McMahon B, Karimkhani C, Yu C, Cooke GS, Schwebel DC, Carpenter DO, Pereira DM, Nash D, Kazi DS, De Leo D, Plass D, Ukwaja KN, Thurston GD, Yun Jin K, Simard EP, Mills E, Park EK, Catalá-López F, deVeber G, Gotay C, Khan G, Hosgood HD 3rd, Santos IS, Leasher JL, Singh J, Leigh J, Jonas JB, Sanabria J, Beardsley J, Jacobsen KH, Takahashi K, Franklin RC, Ronfani L, Montico M, Naldi L, Tonelli M, Geleijnse J, Petzold M, Shrime MG, Younis M, Yonemoto N, Breitborde N, Yip P, Pourmalek F, Lotufo PA, Esteghamati A, Hankey GJ, Ali R, Lunevicius R, Malekzadeh R, Dellavalle R, Weintraub R, Lucas R, Hay R, Rojas-Rueda D, Westerman R, Sepanlou SG, Nolte S, Patten S, Weichenthal S, Abera SF, Fereshtehnejad SM, Shiue I, Driscoll T, Vasankari T, Alsharif U, Rahimi-Movaghar V, Vlassov VV, Marcenes WS, Mekonnen W, Melaku YA, Yano Y, Artaman A, Campos I, MacLachlan J, Mueller U, Kim D, Trillini M, Eshrati B, Williams HC, Shibuya K, Dandona R, Murthy K, Cowie B, Amare AT, Antonio CA, Castañeda-Orjuela C, van Gool CH, Violante F, Oh IH, Deribe K, Soreide K, Knibbs L, Kereselidze M, Green M, Cardenas R, Roy N, Tillmann T, Li Y, Krueger H, Monasta L, Dey S, Sheikhbahaei S, Hafezi-Nejad N, Kumar GA, Sreeramareddy CT, Dandona L, Wang H, Vollset SE, Mokdad A, Salomon JA, Lozano R, Vos T, Forouzanfar M, Lopez A, Murray C and Naghavi M: The Global Burden of Cancer 2013. JAMA Oncol 1: 505-527, 2015. PMID: 26181261, DOI: 10.1001/jamaoncol.2015.0735.

3 Rice TW, Lerut TE, Orringer MB, Chen LQ, Hofstetter WL, Smithers BM, Rusch VW, van Lanschot J, Chen KN, Davies AR, D'Journo XB, Kesler KA, Luketich JD, Ferguson MK, Räsänen JV, van Hillegersberg R, Fang W, Durand L, Allum WH, Cecconello I, Cerfolio RJ, Pera M, Griffin SM, Burger R, Liu JF, Allen MS, Law S, Watson TJ, Darling GE, Scott WJ, Duranceau A, Denlinger CE, Schipper PH, Ishwaran H, Apperson-Hansen C, DiPaola LM, Semple ME and Blackstone EH: Worldwide Esophageal Cancer Collaboration: Clinical staging data. Dis Esophagus 29: 707-714, 2016. PMID: 27731548, DOI: $10.1111 /$ dote.12513. 
4 Demeester SR: Epidemiology and biology of esophageal cancer. Gastrointest Cancer Res 3: S2-5, 2009. PMID: 19461918.

5 Shitara K and Muro K: Chemoradiotherapy for treatment of esophageal cancer in Japan: current status and perspectives. Gastrointest Cancer Res 3: 66-72, 2009. PMID: 19461908.

6 Childers CP, Maggard-Gibbons M, Ulloa JG, MacQueen IT, Miake-Lye IM, Shanman R, Mak S, Beroes JM and Shekelle PG: Perioperative management of antiplatelet therapy in patients undergoing non-cardiac surgery following coronary stent placement: a systematic review. Syst Rev 28: 707-714, 2018. PMID: 29321066, DOI: 10.1186/s13643-017-0635-z.

7 Kolh P, Windecker S, Alfonso F, Collet JP, Cremer J, Falk V, Filippatos G, Hamm C, Head SJ, Jüni P, Kappetein AP, Kastrati A, Knuuti J, Landmesser U, Laufer G, Neumann FJ, Richter DJ, Schauerte P, Sousa Uva M, Stefanini GG, Taggart DP, Torracca L, Valgimigli M, Wijns W, Witkowski A; European Society of Cardiology Committee for Practice Guidelines, Zamorano JL, Achenbach S, Baumgartner H, Bax JJ, Bueno H, Dean V, Deaton C, Erol Ç, Fagard R, Ferrari R, Hasdai D, Hoes AW, Kirchhof P, Knuuti J, Kolh P, Lancellotti P, Linhart A, Nihoyannopoulos P, Piepoli MF, Ponikowski P, Sirnes PA, Tamargo JL, Tendera M, Torbicki A, Wijns W, Windecker S; EACTS Clinical Guidelines Committee, Sousa Uva M, Achenbach S, Pepper J, Anyanwu A, Badimon L, Bauersachs J, Baumbach A, Beygui F, Bonaros N, De Carlo M, Deaton C, Dobrev D, Dunning J, Eeckhout E, Gielen S, Hasdai D, Kirchhof P, Luckraz H, Mahrholdt H, Montalescot G, Paparella D, Rastan AJ, Sanmartin M, Sergeant P, Silber S, Tamargo J, ten Berg J, Thiele H, van Geuns RJ, Wagner HO, Wassmann S, Wendler O and Zamorano JL: 2014 ESC/EACTS Guidelines on myocardial revascularization: The Task Force on Myocardial Revascularization of the European Society of Cardiology (ESC) and the European Association for Cardio-Thoracic Surgery (EACTS) developed with the special contribution o. Eur Heart J 35: 2541-2619, 2014. PMID: 25173601, DOI: 10.1093/ejcts/ezu366.

8 Fleisher LA, Fleischmann KE, Auerbach AD, Barnason SA, Beckman JA, Bozkurt B, Davila-Roman VG, Gerhard-Herman MD, Holly TA, Kane GC, Marine JE, Nelson MT, Spencer CC, Thompson A, Ting HH, Uretsky BF and Wijeysundera DN: 2014 ACC/AHA guideline on perioperative cardiovascular evaluation and management of patients undergoing noncardiac surgery: A report of the American College of Cardiology/American Heart Association Task Force on practice guidelines. J Am Coll Cardiol 64: 77-137, 2014. PMID: 25091544, DOI: 10.1016/ j.jacc.2014.07.944.
9 Hawn MT, Graham LA, Richman JS, Itani KMF, Henderson WG, and Maddox TM: Risk of major adverse cardiac events following noncardiac surgery in patients with coronary stents. JAMA 310: 1462-1472, 2013. PMID: 24101118, DOI: 10.1001/ jama.2013.278787.

10 van Werkum JW, Heestermans AA, Zomer AC, Kelder JC, Suttorp MJ, Rensing BJ, Koolen JJ, Brueren BR, Dambrink JH, Hautvast RW, Verheugt FW and ten Berg JM: Predictors of coronary stent thrombosis: the Dutch Stent Thrombosis Registry. J Am Coll Cardiol 53: 1399-1409, 2009. PMID: 19371823, DOI: 10.1016/j.jacc.2008.12.055.

11 van Kuijk JP, Flu WJ, Schouten O, Hoeks SE, Schenkeveld L, de Jaegere PP, Bax JJ, van Domburg RT, Serruys PW and Poldermans D: Timing of noncardiac surgery after coronary artery stenting with bare metal or drug-eluting stents. Am J Cardiol 104: 1229-1234, 2009. PMID: 19840567, DOI: 10.1016/ j.amjcard.2009.06.038.

12 Kaluza JL, Joseph J, Lee JR, Raizner ME and Raizner AE: Catastrophic outcomes of noncardiac surgery soon after coronary stenting. J Am Coll Cardiol 35: 1288-1294, 2000. PMID: 10758971.

13 Levine GN, Bates ER, Bittl JA, Brindis RG, Fihn SD, Fleisher LA, Granger CB, Lange RA, Mack MJ, Mauri L, Mehran R, Mukherjee D, Newby LK, O'Gara PT, Sabatine MS, Smith PK, Smith SC Jr, Halperin JL, Levine GN, Al-Khatib SM, Birtcher KK, Bozkurt B, Brindis RG, Cigarroa JE, Curtis LH, Fleisher LA, Gentile F, Gidding S, Hlatky MA, Ikonomidis JS, Joglar JA, Pressler SJ and Wijeysundera DN: 2016 ACC/AHA guideline focused update on duration of dual antiplatelet therapy in patients with coronary artery disease: A report of the American College of Cardiology/American Heart Association Task Force on Clinical Practice Guidelines. J. Thorac. Cardiovasc. Surg 152: 1243-1275, 2016. PMID: 27751237, DOI: 10.1016/j.jtcvs.2016.07.044.

14 Palmerini T, Sangiorgi D, Valgimigli M, Biondi-Zoccai G, Feres F, Abizaid A, Costa RA, Hong MK, Kim BK, Jang Y, Kim HS, Park KW, Mariani A, Della Riva D, Genereux P, Leon MB, Bhatt DL, Bendetto U, Rapezzi C and Stone GW: Short- versus long-term dual antiplatelet therapy after drug-eluting stent implantation: an individual patient data pairwise and network meta-analysis. J Am Coll Cardiol 65: 1092-1102, 2015. PMID: 25790880, DOI: 10.1016/j.jacc.2014.12.046.

Received January 3, 2019

Revised January 21, 2019

Accepted January 25, 2019 